\title{
Prebiotics and human health: The state-of-the-art and future perspectives
}

\author{
By Patricia L. Conway
}

\begin{abstract}
Prebiotics stimulate growth and/or activity of some presumably beneficial colonic bacteria and thereby have the potential to improve health, possibly through the actions of fermentation end products including butyrate. Some ingested oligosaccharides and resistant starches elevate levels of bifidobacteria and lactobacilli, and decrease bacteroides, enterobacteria and clostridia. Rodent studies have shown that prebiotic consumption can protect against pathogens, reduce the risk of colon cancer, enhance mineral absorption and influence lipogenesis. However confirmation of effects in humans is needed in clinical studies.

With this wide range of potential applications, prebiotics need to be broadly classified based on microbiological and physiological function. Studies investigating mechanisms of action and the combined effects of prebiotics and probiotics are sparse. Resistant starch also functions as a culture protagonist because it provides enhanced bacterial survival when combined with probiotics. With the availability of a variety of prebiotics and probiotics, the potential exists for providing combinations targeted for specific health related benefits.

Keywords: Beneficial microbes, health benefits, oligosaccharides, prebiotics, resistant starch
\end{abstract}

\section{Introduction}

The term prebiotics refers to the modification of the intestinal microbes and their metabolism for the benefit of the host using food ingredients. While the concept of nurturing intestinal lactobacilli by dietary means dates back to Metchnikoff (1), the term was coined more recently. In 1995 Gibson and Roberfroid (2) defined a prebiotic as a "non-digestible food ingredient that beneficially affects the host by selectively stimulating the growth and/or activity of one or a limited number of bacteria in the colon that have the potential to improve health". The combination of prebiotics with probiotics is referred to as synbiotics. The term prebiotic evolved from the observation that non-digestible carbohydrates selectively promoted levels of bifidobacterium and short chain fatty acids in the large bowel and from the fact that these bacteria are recognised as having the potential to exert health benefits.

Enhancement of bifidobacterium has previously been noted in breast fed babies and is referred to as a bifidogenic effect (3). Consequently, it is reasonable to envisage the term prebiotic encompasses (a) the positive effects on potentially beneficial microbes, including the bifidogenic effect and increases in other beneficial microbes such as lactobacilli, (b) reducing the effects on the less desirable microbes as well as (c) the indirect effects on improving host health and physiology, i.e. a result of the activity of the microbes. As mechanisms of function are understood, these categories can be further expanded and refined.

It is also relevant to question how one interprets the definition of a prebiotic. It refers to effects on "growth and/or activity" of the microbes which would require an increase in beneficial microbes and/or the effects induced by metabolic products obtained from the colonic microbes which would mediate beneficial effects on the health of the host. The published literature at times assumes that the prebiotic effect is the elevation of bifidobacteria and that other effects are outside the definition of a prebiotic (4). With the definition "growth and/or activity", one can expect there could be compounds that have a beneficial effect on health parameters linked to the intestinal microbes, e.g. cancer risk, but that may not induce a detectable elevation of beneficial microbes. To exclude these compounds from being called prebiotics may be limiting to the concept since there could be microbes other than bifidobacteria and lactobacilli which exert a beneficial effect within the colonic ecosystem, either directly or indirectly through the action of their metabolites and end products. As with the bifidobacteria and lactobacilli, it may not be the microbe itself that is beneficial, but rather the results of microbial metabolism and the activity that develops that are more important.

The large bowel microbes require an appropriate nutrient supply. The food components that escape digestion in the small intestine can function as colonic food and be utilised by the large bowel microbes. Prebiotics are not degraded by host enzymes in the small intestine and reach the large bowel where they are selectively utilised by the beneficial bacteria such as lactobacilli and/or bifidobacteria. These microbes have been shown to induce a number of potential health benefits when orally administered $(5,6)$. Bifidobacteria and lactobacilli are considered beneficial, but questions are raised as to the validity of such statements (7).

A recent review (8) noted that oral dosage with some ,but not all, Lactobacillus and Bifidobacterium showed positive effects.

Dietary inulin and oligosaccharides such as fructo-oligosaccharide and galacto-oligosaccharide have been shown to elevate levels of bifidobacteria in faecal samples $(2,9)$ and so do resistant starches (10-12). Since many oligosaccharides are not selectively utilised by the bifidobacteia, one can question the specificity. Commercial oligosaccharides contain a family of fructan compounds with different degrees of polymerisation. If there is no specificity for the differing degrees of molecular size then one would envisage that all components in an oligo-

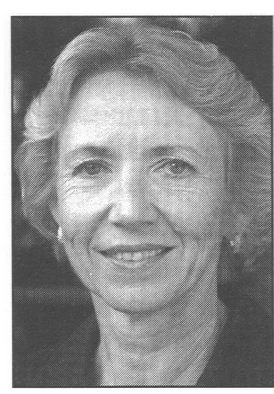

Patricia Conway, PhD, School of Microbiology and Immunology, The University of New South Wales, UNSW Sydney NSW 2052, Australia.

E-mail: P.Conway@unsw.edu.au

The article is based on a lecture presented at the symposium "Probiotics and prebiotics - scientific evidence in humans as a basis for health claims", 14 15 November 2000, arranged by SNF Swedish Nutrition Foundation. 
saccharide preparation are fermented simultaneously and therefore rapidly. While there are extensive clinical trials confirming the elevation of bifidobacteria by oral administration of oligosaccharides (9), the health benefits of prebiotics and synbiotics need to be demonstrated. At present the impact on human health benefits is largely inferred from rodent studies.

\section{Bowel health and the intestinal microbiota}

The digestive tract of humans is sterile at birth and within the first few days of life it becomes colonised by microbes, which in breastfed infants are predominantly bifidobacteria (3). With the introduction of other foods, a diverse microbial population develops in the gastrointestinal tract. While the upper regions of the tract are sparsely populated with microbes, a large microbial community resides in the large bowel (13). While there are over 50 genera and 400 species, the population is predominantly strict anaerobic bacteria such as Bacteroides, Fusobacterium, Bifidobacterium, Lactobacillus and Eubacterium with lower levels of coliforms. These microbes produce essential vitamins and nutrients required by the colonocytes, assist with degradation of complex nutrients, protect the host from invasion by pathogens and stimulate the immune system (13). In addition, it has been proposed that the microbes in the bowel contribute to mineral absorption and lipid metabolism because of the lowered $\mathrm{pH}$ as a result of the short chain fatty acids produced by the microbes. These short chain fatty acids play an important role in maintaining normal bowel function (14).

Some undesirable effects such as flatulence, diarrhoea, constipation, liver damage, irritable bowel syndrome, inflammatory bowel disease and bowel cancer have been linked to the microbes (14-15). Such unfavourable situations can occur if there is a shift in either the composition or metabolism of the indigenous microbes of the healthy individual. While particular microbes are implicated in some conditions, e.g. Clostridium difficile induced diarrhoea as a result of antibiotic administration, it is largely presumptive evidence of the role of these microbes in other conditions. For example, protein and amino acid degradation by the microbes can yield nitrogenous compounds such as ammonia, amines, phenols and indoles that are considered putative risk factors for neoplastic transformations of the colon (15). Bacterial enzymes such as azoreductase, nitroreductase and beta-glucuronidase that are produced in the large bowel by a number of bacterial species, have the capacity of converting cocarcinogens to carcinogens in the bowel $(15,16)$. There is evidence that orally dosed antibiotics can alleviate the symptoms of intestinal disorders linked to gut motility e.g. constipation and irritable bowel syndrome (17), thus implicating the indigenous intestinal microbes in such conditions. While the microbes have been directly linked to inflammatory bowel disease (18), others postulate that it is a result of disordered cytokine production (19). There is accumulating evidence that lactobacilli can trigger cytokine production (20). It is therefore plausible that inflammatory bowel disease can be addressed by controlling the intestinal microbes such that those that trigger a desirable cytokine response are promoted.

The microbial community of the bowel is a part of a complex ecosystem which is regulated by the diet of the host, microbial interactions and host factors such as gut motility and intestinal secretions (13). External factors such as stress, dietary changes and medications can affect the microbial community in the bowel and induce an alteration in the diversity or in the metabolism of the microbes. This can be detrimental to the host, however, it can also be utilised for the benefit of the host. One can maintain a healthy microbial population by dietary means and with orally administered beneficial microbes such as the Lactobacillus and Bifidobacterium in sufficient numbers.

\section{Non-digestible food ingredients}

The digestive enzymes of the host that are responsible for metabolism of ingested nutrients are released in the small bowel where absorption occurs and the indigenous microbial populations are limited. The term "non-digestible food ingredients" refers to those components of the diet which are not degraded and utilised in the small bowel and hence reach the large bowel where they can be fermented by the indigenous microbes. The diversity of the dense population of colonic microbes contributes to the large range of substrates which can be degraded because there are both proteolytic and saccharolytic populations, with the latter being more dominant. Proteins and carbohydrates reach the colon where they are fermented by the microbes. It is estimated that while carbohydrates are predominant (20-76 g/day), approximately 3-9 g/day of proteins enter the large bowel. Endogenous secretions and sloughed cells (6-9 g/day) may also serve as fermentable substrate for the colonic microbes (11).

Carbohydrates which reach the large bowel include the nonstarch polysaccharides (NSPs) such as the soluble and insoluble dietary fibres (8-18 g/day), resistant starch (RS; 8-40 g/day) and non-digestible oligosaccharides (NDOs; $2-8 \mathrm{~g} /$ day). In addition, some sugars (2-10 g/day) such as lactose, fructose and sorbitol which are not completely absorbed in the small bowel may also enter the colon $(14,21)$.

The physiological effects of carbohydrates entering the colon have been extensively investigated, especially in terms of the effects on laxation. While wheat bran has been shown to increase faecal bulk by a factor of 5 when expressed as the stool weight increment per gram of carbohydrate consumed, NSPs such as pectin and guar gums increase stool weight by a factor of 1-2, resistant starches by 1.5-2.2 (22) and non-digestible oligosaccharides by 1.5-2.0 (23). The incompletely fermented NSPs have a physical effect on faecal bulking and induce a variable change in bacterial biomass. In contrast, the effect of the NDOs and RSs on laxation is most probably linked mainly to the increase in bacterial mass in the faeces and the increase in short chain fatty acids generated through fermentation of these carbohydrates by the indigenous microbes (11-12).

It is possible that all these carbohydrates can be utilised by the colonic microbes as a nutrient source and therefore function as a prebiotic if preferentially utilised by beneficial microbes such that numbers or activities are influenced.

\section{Non-digestible oligosaccharides}

Oligosaccharides are low molecular weight carbohydrates with degree of polymerisation (DP) values of between 2 and 9. They are found in chicory, asparagus, artichoke, onions, garlic, leeks and soya beans as well as in human breast milk and cow's milk. The glycosidic bonds are resistant to hydrolysis by intestinal digestive enzymes and hence are poorly degraded in the upper regions of the gastrointestinal tract, thus reaching the colon intact. The colonic microbes ferment the non-digestible oligosaccharides to produce short chain fatty acids and gases such as carbon dioxide, methane and hydrogen. Depending on the nondigestible oligosaccharides (NDOs), this microbial fermentation can occur immediately upon entering the caecum, leading to rapid release of gases.

A method for determining fructan has been approved by the AOAC. Many countries have either accepted fructans as a component or a type of dietary fibre or are now considering acceptance of the method. The term oligosaccharide becomes subjective when discussing prebiotic activities. A number of saccharides have been explored for their prebiotic potential, the most frequently studied ones being presented in Table 1 . These include disaccharides such as lactulose and lacitol, a number of 
Table 1. Source and composition of the non-digestible di-saccharides, oligosaccharides and inulin which have been evaluated most extensively as prebiotics (Rowland, personal communciation).

\begin{tabular}{|c|c|c|c|}
\hline Oligosaccharide & Source & Composition & $\begin{array}{c}\text { Degree of } \\
\text { polymerisation }\end{array}$ \\
\hline Lactulose & Synthetic disaccharide & galactopyranosyl-D-fructofuranose & \\
\hline $\begin{array}{l}\text { Lacitol } \\
\text { Fructo-oligosaccharide }\end{array}$ & $\begin{array}{l}\text { Synthetic disaccharide } \\
\text { a. Sucrose fermentation by Aspergilus niger } \\
\text { b. Transfructosylase + sucrose }\end{array}$ & $\begin{array}{l}\text { galactopyranosyl-D-glucitol } \\
\text { glu-(fru)n } \\
\text { glu-(fru)n }\end{array}$ & $\begin{array}{l}3-5 \\
3-5\end{array}$ \\
\hline Oligofructose & Hydrolysis of chicory inulin & (fru)n+glu-(fru)n & $2-8$ \\
\hline Galacto-oligosaccharide & $\begin{array}{l}\text { a. Human and cow milk; } \\
\text { b. Lactose fermentation by Aspergillus oryzae } \\
\text { c. Galactosidase + lactose }\end{array}$ & $\begin{array}{l}\text { glu-(gal)n } \\
\text { glu-(gal)n }\end{array}$ & $3-6$ \\
\hline Soybean- oligosaccharide & Extracts of soybean whey & Mix of fru-gal-glu and fru-gal-gal-glu & $3-5$ \\
\hline Inulin* & Extracted from chicory root, Jerusalem artichoke & glu-(fru)n; (fru)n & $3-60$ \\
\hline
\end{tabular}

* Heterogenous fructan containing polysaccharides as well as oligosaccharides

oligosaccharides in the true sense of the term as well as inulin which is available commercially as a mixture of various oligosaccharides and longer chain fructans ( $\mathrm{DP}<60 ; 24)$. For the purpose of simplicity, they are often all referred to as oligosaccharides when discussed as prebiotics, however one can not ignore that the different DP values may have different physiological effects. It is reported that the DP value of the saccharide correlated wtih the rate of disappearance as a result of bacterial fermentation with the smaller DP values being more readily fermented.

\section{Oligosaccharides as prebiotics}

\section{(a) Effects on the microbes}

Some of the studies investigating the bifidogenic effects of human consumption of the more common oligosaccharides are summarised in Table 2. It is obvious from this table that the body of published literature available to us deals with the chicory fructans i.e. inulin and its enzymatic hydrolysate, oligofructose and fructo-oligosaccharide. Most studies report an increase in the faecal numbers of bifidobacteria. Similarly, the disaccharide lactulose, soybean oligosaccharide, and galacto-oligosaccharide induce an increase of bifidobacteria. The detected increase is often relatively small but significant in the majority of cases. Even though it is over a decade since the first reports of elevated bifidobacteria in faeces after consumption of oligosaccharides, no large scale studies were found in the literature. This is not surprising in view of the amount of work and hence costs involved in studying the individual faecal microbial profiles of subjects. Unfortunately, with small scale studies there can be a bias in the selection of the subjects which may influence the results. For example, it is often laboratory colleagues or students who participate in such studies and that, in itself implies a bias in selection of the subjects. Because of the diversity of intestinal microbes from subject to subject, one would anticipate a large variation in parameters which are influenced by the composition of the individual microbes and hence large scale studies are required. Most reports use about 10 subjects (25) but fail to report on the dietary habits of these subjects.

Other variables in these studies include the concentration of oligosaccharide consumed and the time span of the study. Because consumption of high levels of oligosaccharides i.e. $>10$ g per day, can lead to intestinal discomfort and flatulence,

Table 2. Elevation of faecal Bifidobacterium levels as a result of oral administration of saccharides to human volunteers.

\begin{tabular}{|c|c|c|c|c|c|c|}
\hline Saccharide $^{\mathrm{a}}$ & $\begin{array}{l}\text { Dose } \\
(\mathrm{g} / \mathrm{d})\end{array}$ & $\begin{array}{l}\text { Duration } \\
\text { (days) }\end{array}$ & $\begin{array}{l}\text { Subjects } \\
\text { per group }\end{array}$ & $\begin{array}{l}\text { Initial Count } \\
\mathrm{LogCFU} / \mathrm{g}\end{array}$ & $\begin{array}{l}\text { Final Count } \\
\mathrm{Log} C F U / g\end{array}$ & Ref \\
\hline Lactulose & 3 & 14 & 8 & 9.7 & $10.4^{\mathrm{b}}$ & 58 \\
\hline Lactulose & 20 & 28 & 12 & 8.5 & $11.5^{\mathrm{b}}$ & 52 \\
\hline SoybeanOS & 10 & 21 & 6 & 9.5 & $10.0^{\mathrm{b}}$ & 59 \\
\hline GOS & 10 & 7 & 12 & 9.8 & $10.1^{\mathrm{b}}$ & 57 \\
\hline GOS & 15 & $7,14,21$ & 8 & $8.6^{c}$ & $9.7^{b}, 9.7^{b}, 9.5^{b}$ & 54 \\
\hline GOS & 7.5 & 21 & 13 & 9.8 & 9.7 & 46 \\
\hline GOS & 15 & 21 & 13 & 9.8 & 9.7 & 46 \\
\hline FOS & 12.5 & 12 & 10 & 7.9 & $9.1^{b}$ & 55 \\
\hline FOS & 4 & 14 & 10 & 8.8 & 9.6 & 53 \\
\hline FOS & 10 & 8 & 8 & 8.0 & $9.5^{b}$ & 92 \\
\hline $\mathrm{OF}$ & 15 & 15 & 8 & 8.8 & $9.5^{b}$ & 42 \\
\hline Inulin & 15 & 15 & 8 & 9.2 & $10.1^{b}$ & 42 \\
\hline Inulin & $20^{\mathrm{d}} ; 20$ to $40^{\mathrm{e}} ; 40^{\mathrm{f}}$ & $7^{\mathrm{d}} ; 3^{\mathrm{e}}, 7^{\mathrm{f}}$ & 10 & 7.9 & $9.2^{b}$ & 56 \\
\hline Inulin & 34 & 64 & 8 & 9.8 & $11.0^{\mathrm{b}}$ & 51 \\
\hline Inulin & 8 & $14+21$ & 8 & 8.6 & $9.6^{\mathrm{b}}, 9.4^{\mathrm{b}}$ & 121 \\
\hline
\end{tabular}

a oligosaccharide (OS), galacto-oligosaccharide (GOS), fructo-oligosaccharide (FOS), oligofructose (OF)

${ }^{\mathrm{b}}$ Significantly different from initial value $(\mathrm{P}<0.05) ;{ }^{\mathrm{c}}$ value at day $1 ;{ }^{\mathrm{d}}$ e,f different doses for different duration $($ days $)$ 
Table 3. Prebiotic effects of oligosaccharides as seen from rodent $(\mathbf{R})$, pig (P) and human (H) studies.

Effects on the microbes

- Bifidobacterium counts increase $(\mathrm{H})$

- Lactobacillius counts sometimes increase $(\mathrm{H})$

- Clostridia and enterobacteria sometimes decrease (H)

- Reduced shedding of S. typhimurium (P)

Effects on host health and physiology

- Reduction in blood lipids ( $\mathrm{R}$ positive; $\mathrm{H}$ no clear indication)

- Increased mineral absorption ( $\mathrm{R}$, calcium and magnesium; $\mathrm{H}$, positive for calcium)

- Reduced risk of cancer development (R)

there is considerable interest in identifying minimum levels required for obtaining elevated levels of bifidobacteria. Rao (26) reviewed the dose in relation to the extent of the elevation of the bifidobacteria. It was noted that even though the dose of saccharide ranged from 8 to $40 \mathrm{~g}$ per day, there was no correlation with the resultant elevation of bifidobacteria. Furthermore, consumption of $80 \mathrm{~g}$ per day of oligofructose in one study gave only 4 of 12 test subjects diarrhoea (27).

The pre-treatment levels of bifidobacteria could play a role in the extent of elevation of bifidobacterium. It is probable that if there already are high levels of bifidobacteria, it would be more difficult to show elevations. The baseline level of bifidobacterium may be as important a parameter as the magnitude of the increase and the method used for enumeration of the bifidobacterium. When reviewing the effects of oligosaccharides, Roberfroid (28) noted that the lower the initial bifidobacteium levels, the greater the increase noted with oligosaccharide consumption. The studies presented in Table 2 use selective media for enumeration of the viable colony forming units. The accuracy of this methodology is limited by the selectivity of the medium used. It is recognised that there are limitations with the various media used because the more selective the media, the more risk that it will exclude cultivation of some of the more sensitive species while the use of the less selective media runs the risk of including non-bifidobacteria in the count of bifidobacteria (29). Studies are in progress to use molecular approaches to study effects of prebiotics and probiotics on the intestinal microbial populations (30). The ribosomal RNA (rRNA), in particular the $16 \mathrm{~S}$ rRNA, is used extensively for classification and detection and there is now an extensive database of $16 \mathrm{~S}$ sequences. Using rRNA targeted oligonucleotide probes end-labelled with fluorescent dyes, in situ hydridisation can be used to quantify specific genera in faecal samples. This methodology has been used to effectively quantify bifidobacteria in humans consuming a prebiotic (31).

While most studies focus on the bifidobacteria (Table 2) (3236), some studies also report increased levels of lactobacilli. For example, Ito et al. (37) showed a dose related significant $(\mathrm{P}<0.001)$ increase in faecal lactobacilli in 12 subjects consuming galacto-oligosaccharide for 7 days. In addition to elevated levels of beneficial microbes, decreases in less desirable microbes had been noted in some studies. A decrease in faecal clostridia and bacteroides was reported in 8 subjects consuming 3 g per day lactulose (38) and other workers (39) report a decrease in Clostridium perfringens with consumption of $10 \mathrm{~g}$ per day of soybean oligosaccharide in 6 subjects. Benno et al. (40) show a decrease in clostridia and bacteroides with consumption of $15 \mathrm{~g}$ per day but not with 3-5 g per day of raffinose. A reduction in the shedding of Salmonella typhimurium in pigs was observed with consumption of fructo-oligosaccharide without any detectable effects on other microbial groups investigated (41). Further proof of the possibility of reducing the less desirable microbes could be obtained by conducting pathogen challenge studies in animal models.

\section{(b) Effects on host health and physiology}

It is well known that breast fed babies have high faecal levels of bifidobacteria while in formula fed babies there are high levels of anaerobic bacteria as well (reviewed by 3 ). It is presumed that oligosaccharide components naturally occurring in breast milk induce this effect since breast fed babies are more resistant to infection. There is accumulating evidence that consumption of oligosaccharides can result in health benefits (Table 3 ).

A number of studies have addressed the effects of oligosaccharides on serum lipids. It is proposed that short chain fatty acids (SCFA) from microbial fermentation in the intestine are absorbed and modulate hepatic lipogenesis. In addition to this regulation of hepatic synthesis of triglycerides and cholesterol, it is proposed that serum cholesterol may be reduced because of precipitation and excretion of bile acids from the intestine which then requires the liver to utilise cholesterol for further bile acid synthesis (42). Bile acids are precipitated as a result of bacterial deconjugation and acidification by the SCFA. Rodent studies have demonstrated a conclusive reduction in serum lipids, however, there has been no clear indication from human studies that this is the case (reviewed by 24). Fructo-oligosaccharide (43) consumption has lead to a lowered concentration of triglycerides and cholesterol in rats. Others workers $(44,45)$ report a lowering of serum cholesterol in rats given either fructooligosaccharide or galacto-oligosaccharide. In rodent studies the oligosaccharides were included at a level of $10-20 \%$ of the diet which was given to the animals for 4-5 weeks. In human studies the amount given generally ranges from 8 to $14 \mathrm{~g}$ per day over a 3-4 week period. One can question whether a longer term study or a higher dose would provide more conclusive data in humans. In one study (46) $10 \mathrm{~g}$ per day of inulin was given for 8 weeks and resulted in a decrease of triglycerides but no change in cholesterol. Inulin given at a level of $14 \mathrm{~g}$ per day for 4 weeks failed to alter triglycerides and cholesterol levels (42). Other workers administered $34 \mathrm{~g}$ per day for 64 dys and failed to show any effects on blood lipids (31). A decrease in cholesterol but not in triglycerides was noted after consumption of inulin at a level of $18 \mathrm{~g}$ per day for 3 weeks by hyperlipidemic human subjects (42). Decreased basal hepatic glucose production and unchanged in insulin stimulated glucose metabolism was noted in human subjects given $20 \mathrm{~g} / \mathrm{d}$ of fructo-oligosaccharides for 4 weeks (48).

Several studies have investigated the effects of oligosaccharide consumption on mineral absorption. Rats fed lactulose (49), fructo-oligosaccharide (50) or inulin (51) absorbed more calcium and magnesium than control animals. Furthermore, it was shown that parameters resulting from increased mineral absorption were also improved. Oligofructose increased bone mineral content in rats (52) and chronic ingestion of inulin or fructooligosaccharide decreased the loss of bone mass, calcium and phosphorus from the bones of rats (53). Although there are some conflicting reports, positive effects on absorption of calcium in humans have been reported. Coudray et al. (54) showed an increase from $21 \%$ to $34 \%$ of calcium absorption when measuring the mineral balance in urine and faecal samples from males ingesting $40 \mathrm{~g}$ per day of inulin for 28 days in a study using 9 healthy subjects. These workers showed no effects on magnesium, iron or zinc absorption. Consumption of oligofructose, galacto-oligosaccharide or inulin ( $15 \mathrm{~g}$ per day) for 3 weeks did not induce an increase in calcium or iron absorption in males aged $20-26$ years old ( 12 subjects) (55), whereas the same 
group could demonstrate an increase in calcium absorption when the method had been modified to measure the absorption over 36 hours and used in younger subjects (14-16 years old) (56).

A number of possible explanations for the increased mineral absorption have been proposed. It is proven that oligosaccharide ingestion can raise the colonic levels of short chain fatty acids which will reduce $\mathrm{pH}$, thus raising the concentration of calcium and magnesium ions which can passively diffuse. It is also likely that the oligosaccharides will increase water content and thus increase the solubility of some minerals. It is also proposed that there could be increased permeability of intracellular junctions. While further studies are required to confirm the mechanisms involved, it is apparent that calcium absorption in humans can be influenced by oligosaccharide consumption.

The effects of oligosaccharide ingestion on irritable bowel syndrome (IBS) and on Type 2 diabetes has been examined in separate studies but no positive effects were observed. The diabetes subjects consumed $20 \mathrm{~g}$ per day of fructooligosaccharide for 4 weeks (57). In a double blind, placebo controlled crossover study of 21 subjects with IBS, $6 \mathrm{~g}$ per day of oligofructose for 4 weeks did not alter the faecal weight or $\mathrm{pH}$, transit time or breath hydrogen compared to that observed during the control period using sucrose (58). An accelerated recovery of the intestinal microbes was noted in pigs after an acute secretory diarrhoea using fructo-oligosaccharide supplementation (59).

Effects of oligosaccharides on the risks of colon cancer have been investigated by measuring bacterial metabolites associated with carcinogenesis e.g. enzymes and ammonia, as well as the extent of DNA damage in vivo as measured using the Comet assay, the suppression of pre-neoplastic changes in the colon measured as aberrant crypt foci (ACF) and the suppression of tumours when animals are exposed to a carcinogen. The enzymes $\beta$-glucuronidase and nitroreductase decreased in rats fed galacto-oligosaccharides, however $\beta$-glucosidase increased in these animals (60). A diet containing 3\% lactulose induced less cellular DNA damage detected using the Comet assay when rats were exposed to a carcinogen (61). In two independent studies (62.63), a suppression of ACF formation was noted in rats fed inulin for 12 weeks after induction using azoxymethane. Reddy and co-workers also showed similar effects with $10 \%$ fructooligosaccharide, however the effect was not as great as observed for inulin. This is probably attributable to the fact that since the inulin is more slowly degraded, it will pass further along the colon before being completely degraded and hence induce effects in the more distal regions of the colon. It is recognised that cancer development is greatest in the distal colon. Inclusion of $15 \%$ oligosaccharide or inulin in the diet of mice implanted with tumour cells showed a significant reduction in the growth of the tumour (64). Similarly it has been shown that inclusion of $5.8 \%$ oligofructose in the diet resulted in a reduction in small intestinal and colonic tumours in mice (65). Oligofructose $(5 \%)$ or inulin $(5 \%)$ consumption for 3 weeks had no significant effect on bacterial enzymes or ammonia levels, however, the oligofructose or inulin diet induced a significantly higher apoptosis index in rats (66). Other workers (67) reported that inulin consumption stimulated the production of sulphomucin and a reduction in sialomucin, two effects that are associated with a reduced risk of colon cancer (68). No epidemiological studies were found which correlated the occurrence of cancers in populations consuming high or low levels of dietary oligosaccharides and fructans.

The bacterial fermentation of oligosaccharides in the colon leads to the production of acids and gas. While this can lead to beneficial effects on the host, it can also cause intestinal discomfort, pain, diarrhoea and flatulence. The effects are more pronounced with the short chain oligosaccharides such as the
Table 4. Classification of resistant starches (74).

\begin{tabular}{|c|c|c|}
\hline Group & Basis of resistance & Source \\
\hline $\mathrm{RS}_{1}$ & Physically inaccessible & $\begin{array}{l}\text { Seeds, whole grains and } \\
\text { partly milled grains }\end{array}$ \\
\hline $\mathrm{RS}_{2}$ & Granular & $\begin{array}{l}\text { Green bananas, raw potato, } \\
\text { some legumes and high } \\
\text { amylose starches }(>80 \%)\end{array}$ \\
\hline $\mathrm{RS}_{3}$ & Retrograded & $\begin{array}{l}\text { Cooked and cooled potato, } \\
\text { bread and cornflakes }\end{array}$ \\
\hline $\mathrm{RS}_{4}$ & Chemically modified & $\begin{array}{l}\text { Cross-bonded, etherised or } \\
\text { esterified starch }\end{array}$ \\
\hline
\end{tabular}

oligofructose compared to the long chains. It has been shown that the inulin is more slowly fermented than the short chain fructooligosaccharides (69). Bouhnik et al. (70) noted that $10 \mathrm{~g}$ per day for 8 days gave flatulence, however if the level was maintained below $10 \mathrm{~g}$ per day, no discomfort was noted. It can therefore be envisaged that in the future, oligosaccharides that are more uniformly fermented through the colon will be sought to ensure a beneficial effect throughout the length of the colon and to reduce the adverse effects of the rapid fermentation in the proximal regions.

\section{Resistant starch}

For many years, it was assumed that non-starch polysaccharides (NSP) were the principal substrates for fermentation in the large bowel because little starch appeared in the faeces (71), It became apparent that NSP could not supply the entire substrate requirements for the microbes and then resistant starch (RS) became a potential candidate substrate (72). RS is defined as "the sum of the starch and products of starch degradation not absorbed in the small intestine of healthy individuals" $(73,74)$ and it was shown that a substantial quantity of dietary starch enters the large bowel where is is fermented $(74,75)$. The digestibility of starch in the ileum can be affected by a number of factors including the physical inaccessibility of the starch $\left(\mathrm{RS}_{1}\right)$ e.g. in coarsely ground cereal grains. In addition, the granular structure or conformation of the starch $\left(\mathrm{RS}_{2}\right)$ and/or the degree of retrogradation of the starch after cooking $\left(\mathrm{RS}_{3}\right)$ can limit the digestibility of the starch and influence the amount of starch reaching the colon and which is therefore available as fermentable substrate. Chemical modifications of starches can also increase the resistance of the starch to digestion. Accordingly, resistant starches are grouped into four general categories, namely $\mathrm{RS}_{1}$, $\mathrm{RS}_{2}, \mathrm{RS}_{3}$ and $\mathrm{RS}_{4}$ as detailed in Table 4 (74). Starch contains two main components, amylose and amylopectin. Most starches contain mainly amylopectin (often 70-80\%) which is an extremely large glucose polymer (10,000-100,000 monomers units) containing $\alpha-(1-6)$ branch points. Starch granules that contain a high proportion of amylopectin generally have a lower gelatinisation temperature and are normally readily digestible. The amylose found in starches is essentially a linear polymer (100-10,000 monomer units) of $\alpha(1-4)$ linkages and is mainly found in the amorphous regions of starch granules. Some specific maize cultivars have starch granules that can contain more than $80 \%$ amylose and that are resistant to gelatinisation under normal cooking conditions (12). In maize, the resistance of the granule to digestion increases with increasing amounts of amylose (76). After gelatinisation, the high amylose content leads to a rapid retrogradation of the starch on cooling. This process yields insoluble crystallites which resist enzymatic hydrolysis $(77,78)$. 
Table 5. The prebiotic properties of resistant starches generated from rodent $(R)$, porcine $(P)$ and human $(H)$ studies (Modified from 12).

Effects on microbes

- Selectively utilized by bifidobacteria cultures in vitro $(\mathrm{H})$

- Promotes growth of lactobacilli and bifidobactera (R, P):

- Reduce intestinal pathogen levels (R)

- Synbiotic promotion of beneficial indigenous effects (R)

- Synergy with oligosaccharides (R, P) - elevation of indigenous bifidobacteria

- Modified amylomaize regulates bacterial growth in vivo (R)

- Enhanced survival of probiotic cultures (Culture Protagonist)

Effects on host health and physiology

- Reduce symptoms of diarrhoea (duration and fluid loss) (H)

- Elevate colonic butyrate levels (H)

- Increased Ca and Mg absorption (R)

- Reduced risk of colon cancer $(\mathrm{R})$

The extent of degradation of starch in the small intestine and hence the amount of resistant starch i.e. the amount entering the large bowel, is also influenced by host factors since the extent the starch is chewed and the time taken to pass through the small intestine will affect the amount of hydrolysis that occurs. It is therefore difficult to accurately specify amounts of dietary resistant starch and in fact, Annison and Topping (75) described RS in terms of "physiological" and "chemical" resistant starch. The latter RS refers to that quantified by chemical analysis using in vitro incubations with amylase and amyloglucosidase (79).

\section{Resistant starch as a prebiotic}

\section{(a) Effects on the microbes}

A high amylose maize (amylomaize) starch obtained by conventional plant breeding to contain greater than $80 \%$ amylose, was shown to improve the faecal short chain fatty acid profiles in humans as well as functioning as a dietary fibre with laxation properties $(10,80,81)$. This triggered interest in the bacterial fermentation of amylomaize starch. Over 40 colonic microbes typically found in the human colon were screened for their capacity to utilise the amylomaize starch granules. It was shown that it was almost exclusively the Bifidobacterium spp which could utilise the starch granules as the sole carbon source and that in fact the bifidobacteria grew in starch as well as they grew in the control glucose medium (82). In this study, it was also noted that Clostridium butyricum could also utlise the starch. Although many of the clostridia are known pathogens, Clostridium butyricum is used as a probiotic since oral administration has been shown to lead to a reduction in Clostridium difficile during antimicrobial therapy (83) and in colitis in an animal model (84). In addition, it was shown that faecal butyrate levels were elevated in mice and pigs consuming a synthetic diet based on the amylomaize starch granules $(10,81,85)$. The mice had undetectable levels of bifidobacterium at the commencement of the study $(<\log 2$ cfu per gram) and after 4 weeks on the amylomaize diet, $\log 8.3 \mathrm{cfu}$ per $\mathrm{g}$ faeces were noted (85). The amylomaize diet also lead to an elevation of lactobacilli that would not have been anticipated since no lactobacilli could utilise the amylomaize starch in vitro. One can postulate that the amylomaize granules are initially partially degraded by the bifidobacteria which have a cell wall bound amylase (82), thus releasing sugars which are utilised by the lactobacilli.

Consumption of a retrograded starch, Crystalean, increased both bifidobacteria and lactobacilli in human microflora associated rats (86). Similarly, Kleesen et al. (87) showed an increase in faecal levels of bifiodbacteria in rats fed a raw potato starch of the $\mathrm{RS}_{2}$ type.
The inclusion of the amylomaize starch in the diet also decreased less desirable microbes such as coliforms as shown by Bird et al. (79) in pigs and Wang and co-workers in mice (Manuscript). The rats fed the retrograded starch, Crystalean, also had lowered levels of enterobacteria and staphlococci (86).

Chemically modified amylomaize starch has also been studied. Some modifications favour the proliferation of lactobacilli both in vitro and in vivo and the various modifications can be used to specifically select for desired populations in situ (85).

The prebiotic potential of resistant starch is summarised in Table 5 . There is a sparcity of human clinical trials. Attention has initially focused on the effects of the resistant starch on the microbes and studies are now in place to address the health promoting benefits. Comparisons of the prebiotic effects of resistant starch and oligosaccharides are also lacking. Pigs orally dosed with a Bifidobacterium longum and fed an amylomaize starch diet had higher levels of faecal bifidobacterium than pigs fed a fructooligosaccharide based diet. Interestingly the combination of amylomaize starch and the fructooligosaccharide yielded higher levels of faecal bifidobacteria (81)

\section{(b) Effects on host health and physiology}

The effects of consumption of resistant starches on health and host physiology are summarised in Table 5 . As can be anticipated from the fact that consumption of starch led to an elevation of bifidobacteria and lactobacilli in starch fed mice, health parameters which have been linked to the indigenous microbes of the intestine can be influenced by ingestion of the resistant starch, suggestive of an alteration in the activity of the intestinal microbes for the benefit of the host.

The administration of an oral rehydration therapy supplemented with amylomaize starch granules reduced both the duration and severity of diarrhoea in adult cholera sufferers (88). The duration of the diarrhoea was shortened by $50 \%$ in those subjects receiving the resistant starch, and there was also a reduction in the faecal fluid loss over 48 hours when starch was included in the therapy. These findings are consistent with our own studies in rodents challenged with Salmonella typhimurium. The short chain fatty acid butyrate, which is used as the metabolic fuel for the colonocytes, and which has been linked to a reduced risk of colon cancer, was selectively increased in animals fed an amylomaize based diet (85). Elevated levels of butyrate have also been shown in human subjects consuming a diet rich in the amylomaize starch granules (80). High levels of butyrate could be anticipated to lead to a reduced risk of colon cancer since the butyrate has been shown to reduce the incidence of damage to the DNA as occurs in cancer cells. Consistent with these findings, Rowland and co-workers (86) have used the Comet Assay to show a significant reduction $(\mathrm{P}<0.05)$ in the $\mathrm{DMH}$-induced damage in colonic epithelium of rats fed a retrograded starch, Crystalean. The resistant starch fed mice were significantly different to the sucrose fed controls.

In another study (89), rats fed a retrograded high amylose starch had higher levels of glutathione S-transferase (GST), an enzyme associated with a decreased burden of exposure to reactive carcinogens. One human study involving 12 healthy volunteers (90) showed that consumption of an amylomaize starch diet (55 g RS/d) for 4 weeks resulted in a $26 \%$ decrease $(\mathrm{P}<0.05)$ in bacterial beta-glucosidase, as well as a $30 \%$ decrease $(\mathrm{P}<0.05)$ in total and secondary bile acids. No effect on primary bile acids compared to a low resistant starch $\operatorname{diet}(7.7 \mathrm{~g} \mathrm{RS} / \mathrm{d})$ was noted. Other workers showed no significant difference in SCFA levels, bile acid concentrations or cytotoxicity of faecal waters with the inclusion of amylomaize starch or retrograded amylomaize starch at the level of $32 \mathrm{~g} \mathrm{RS} / \mathrm{d}$ for one week (91).

While it is difficult to show that ingestion of resistant starch 
can reduce the risks associated with colon cancer, a recent study contains some interesting findings which support the hypothesis that risks of colon cancer can be reduced. It is recognised that black South Africans have a low intake of non-starch polysaccharide dietary fibre compared to their white counterparts who have a 30 fold higher incidence of colon cancer (92). It is reported that the black population regularly consumes a porridge which is served cold and hence contains high levels of retrograded resistant starch. This work is in accordance with the report of Cassidy (93) showing a correlation between resistant starch consumption and the incidence of colon cancer.

The potential for resistant starch to improve mineral absorption has been evaluated in one rodent study in which rats were fed either an $\mathrm{RS}_{2}$ or an $\mathrm{RS}_{3}$ type resistant starch. Rats fed the $\mathrm{RS}_{2}$ starch showed increased calcium and magnesium absorption while $\mathrm{RS}_{3}$ had no effect (94). This work holds promise and needs to be expanded in human trials.

\section{Potential prebiotics}

It is feasible that may compounds have the potential to function as prebiotics and it is anticipated that there will be other classes of compounds being explored for prebiotic potential in the future. While this could include proteins, it is most likely that the saccharides will obtain most attention. In fact some of the nonstarch polysaccharides have already been considered. Michel et al. (95) has studied the prebiotic potential of acacia gums and showed that two different gums increase bifidobacteria while one type also elevated lactobacillus numbers. Both of the tested acacia gums decreased numbers of Clostridium and both induced an increase in short chain fatty acids. In another study, consumption of Spirulina platensis resulted in an increase in lactobacillus numbers (96). Alginate that is used widely in the food industry has also been shown to promote beneficial faecal microbes when orally administered to humans (97). Another potential prebiotic is $\beta$-glucan. Lactobacilli and bifidobacteria were enhanced in the presence of $1 \% \beta$-glucans of yeast origin in faecal batch cultures. It was also shown that consumption of a diet rich in $\beta$-glucans increased numbers of faecal lactobacilli and bifidobacteria in mice and provided protection against an oral challenge of Salmonella typhimurium or Clostridium difficile (98). This study with mice also showed that $<20 \%$ of the glucan was degraded in the small intestine while $>80 \%$ was degraded by the time it had passed the large intestine of the mice. This work supports further investigations into the prebiotic properties of $\beta$ glucan.

\section{Synbiotic activity}

A synbiotic is described as the combination of a prebiotic and a probiotic (2). The term implies synergy between the two, and one could envisage that by specifically selecting probiotic strains that have the capacity to utilise the prebiotic, enhanced benefits would be detectable. Unfortunately the combination of prebiotics and probiotics has been studied to a limited extent and further work is needed to validate the concept. Interestingly, the combination of resistant starch with probiotic cultures has led to enhanced survival of the probiotic (99).

\section{Elevation of bifidobacteria}

Bouhnik et al. (35) fed bifidobacteium to subjects with and without inulin dosage $(18 \mathrm{~g} / \mathrm{d})$. No added benefit of the inulin were noted, however, the bifidobacteria increased from $\log 7.7$ to $\log 9$ in the absence of inulin and they proposed that perhaps higher levels of bifidobacteria can not be achieved in those subjects. Should that be the case, no synbiotic effect could be demonstrated. Others (100) fed lactobacillus milk with oligofructose for 7 weeks and reported an increase in bifidobacteria, a decrease in lactobacilli, an increase in total anaerobes, and no change in the coliforms, but no synbiotic effect was noted.

Promotion of faecal bifidobacterium has been shown in pigs orally dosed with Bifidobacterium longum and fed a resistant starch based diet alone or together with fructo-oligosaccharides (81). These workers showed that the fructo-oligosaccharide and starch fed pigs had significantly higher levels of bifidobacteria than were detected in the controls fed only the bifidobacteria, namely $\log 11$ and $\log 11.74$ respectively. In addition, the combination of the oligosaccharide with the starch showed a synergistic effect with $\log 12.02$ detectable faecal bifidobacteria (significantly greater; $\mathrm{P}<0.01$ ). Perhaps the term synbiotic needs to be further defined to refer to combinations of prebiotics and probiotics and/or combinations of prebiotics which stimulate the beneficial colonic bacteria and/or which improve health of the host by either reducing undesirable bacteria or by improving the host physiology. The combination of different prebiotics may yield a combination that enhances fermentation throughout the entire length of the large intestine, since some oligosaccharides will be rapidly utilised and the resistant starches may be more slowly degraded. One study investigated the combination of wheat bran with resistant starch in the diet of pigs. The wheat bran shifted fermentation of the resistant starch further distally and resulted in significantly higher concentrations of butyrate and lower ammonia in the distal colonic regions (101).

The use of synbiotics for reducing the risk of colon cancer has also been investigated to a limited extent. Reddy et al. (102) showed a suppression in the development of abberant crypt foci (ACF) when inulin or oligofructose $(10 \%$ of the diet) was ingested together with a Bifidobacterium longum. Similarly, Rowland et al. (63) observed a significant reduction in preneoplastic lesions when $B$. longum was given orally together with inulin. The suppression was noted during the promotional phase of development of the lesions and shown to be more efficient than either the B. longum or the inulin alone. A reduction was observed in the total number of $\mathrm{ACF}$, the number of foci with one to three aberrant crypts per foci and the number of large foci (four or more aberrant crypts per foci).

\section{Improved robustness of probiotics}

Bifidobacteria adhere to the amylomaize starch granules and are more resistant to undesirable conditions when associated with the granules. It is shown that the amylomaize starch can protect the probiotic bacteria from low $\mathrm{pH}$ and bile acids and hence ensure more viable probiotic cells in the gastrointestinal tract (99). In this study, survival of Bifidobacterium cells at low $\mathrm{pH}$ and in the presence of bile acids was investigated in the absence and presence of amylomaize starch granules. The presence of amylomaize starch granules resulted in enhanced survival with 1000 times more viable cells exposed to low $\mathrm{pH}$ and 100 times more cells in the presence of bile acids. A 10-fold increase in recovery rates of an orally administered Bifidobacterium strain was obtained in vivo when the amylomaize starch granules were included with the Bifidobacterium cells prior to oral administration. Furthermore, the addition of the amylomaize starch to low $\mathrm{pH}$ foods such as yoghurt, can improve the survival of probiotic bacteria in the yoghurt. Probiotic preparations will be more efficacious if the viability can be maintained both in the food and in the digestive tract. The culture protagonist activity of oligosaccharides has not yet been explored, however, it has been reported that fructo-oligosaccharide improves the resistance of a Bifidobacterium animalis strain to bile acids when compared to glucose and fructose (103). This effect was not demonstrable when these authors used a strain of Bifidobacterium breve and a Bifidobacterium longum. This capacity to improved robustness of probiotic cultures is not covered by the prebiotic definition 
and therefore needs to be defined separately. The term Culture Protagonist is proposed to refer to a component that promotes the survival of probiotics during production and storage, in the food and within the digestive tract.

\section{Conclusions and future perspectives}

It is well established that ingestion of prebiotics can elevate indigenous bifidobacterium and lactobacillus levels in the colon. While there is a body of evidence that oligosaccharides elevate desirable bacteria, resistant starch prebiotic work is in its infancy. Further clinical trials are needed to demonstrate the positive effects on health of prebiotics and synbiotics. These studies would be strengthened by understanding mechanisms of function, and by the application of molecular tools for characterising alterations in the microbial profiles of the colonic microbes. The function of resistant starch granules, and possibly other structural elements such as plant cell-wall fragments, as culture protagonists, needs further evaluation. The ideal prebiotic could be developed for specific applications by using a check list which identifies the following parameters:

(a) how rapidly the prebiotic will be utilised, $(b)$ where in the tract it will be utilised, $(c)$ to what extent it will be fermented, $(d)$ which particular indigenous microbes will be enhanced and which will be suppressed $(e)$ identification of the fermentation products.

The development of novel prebiotics that are target and site specific will allow added heath benefits to be achieved. It is envisaged that poor health conditions that are linked to the indigenous microbes can be influenced by the application of prebiotics and synbiotics.

\section{ACKNOWLEDGEMENTS}

The author thanks Prof. Ian Rowland for sharing his findings and Prof Ian Brown for his valuable comments on the manuscript and his challenging questions on the relevance of data and perceptions.

\section{REFERENCES}

1. MetchnikoffE. The prolongation of life. 1st ed. New York: Putnam Sons, 1908

2. Gibson GR, Roberfroid MB: Dietary modulation of the human colonic microbiota-introducing the concept of prebiotics. J Nutr 1995;125:1401-12.

3. Conway PL: Acquisition and Succession of the gut microflora. In: The gastrointestinal microflora eds. Mackie R.I, White BA.Isaacson RE: New York: International Thomson Publishing. 1996;2,pp. 3-38.

4. Roberfroid MB: Prebotics and Synbiotics - Concepts and Nutritional Properties. Br J Nutr 1998;4:5197-5202.

5. Mattila-Sandholm T: The PROBDEMO project: Demonstration of the Nutritional Functionality of Probiotic Foods. Trends in Food Science \& Techn 1999; 10:385-6.

6. Salminen S: Human studies on probiotics: Aspects of scientific documentation. Scand J Nutr 2001;45:8-12

7. Berg RD: Probiotics, prebiotics or conbiotics. Trends in Microbiology. 1998;6:89-92.

8. Pathmakanthan S, Meance S, Edwards CA: Probiotics: A review of human studies to date and methodological approaches. Microbial Ecol Health Dis 2000Suppl 2:10-30.

9. Crittenden RG: Prebiotics. In: Probiotics: A Critical Review, Horizon Scientific Press, Wymondham, UK 1999;141-56.

10. Brown I, Warhurst J, Arcot M, Playne M, Illman RJ, Topping DL: Fecal numbers of bifidobacteria are higher in pigs fed Bifidobacterium longum with a high amylose cornstarch than with a low amylose cornstarch. J Nutr 1997:127:1822-7.

11. Bird AR, Brown, IL, Topping DL: Starches, resistant starches, the gut microflora and human health. Curr Issues Intest Microbiol 2000;1:25-37.

12. Brown I, Conway P, Topping D. The health potential of resistant starches in foods. An Australian perspective. Scand J Nutr 2000;44:53-8.

13. Conway, PL: Microbial ecology of the human large intestine. In: Macfarlane \& Gibson, eds. Human Colonic Microflora, CRC Press 1996;1-24

14. Cummings JH, Macfarlane GT: The control and consequences of bacterial fermentation in the human colon. J Appl Bacteriol 1991;70:443-59.

15. Bingham SA: High-meat diets and cancer risk. Proc Nutr Soc 1999;58:243-8.

16. Hirayama $\mathrm{K}, \mathrm{Rafter} \mathrm{J}$ : The role of lactic acid bacteria in colon cancer prevention: mechanisitc considerations. Antonie van Leeuwenhoek 1999;76:391-4.

17. King TS, Ella M, Hunter JO: Abnormal colonic fermentation in irritable bowel syndrome. Lancet 1998:352:1187-9.

18. Lisby G, Andersen J, Engbaek K, Binder V: Mycobacterium paratuberculosis in intestinal tissue from patients with Crohn's disease demonstrated by a nested polymerase chain reaction. Scand J Gastroenterol 1994;29:923-9.

19. Topping DL, Bird AR: Foods, nutrients and digestive health. Australian J
Nutr Dietetics 1999;56:522-42

20. Isolauri E. Sutas Y. Kankaanpaa P. Arvilommi H. Salminen S. Probiotics: effects on immunity. Am J Clin Nutr. 2001;73(2 Suppl S):444S-450S

21. Baghurst PA, Baghurst KI, Record SJ: Dietary fibre, non-starch poly saccharides and resistant starch - a review. Food Australia 1996;48:S1-S35.

22. Cummings JH, Bingham SA, Heaton KW, Eastwood MA: Fecal wieght, colon cnacer risk and dietary intake of non-starch polysacchairdes (dietary fiber). Gastroenterology 1993;103:1783-9.

23. Gibson GR, Beatty ER, Wang X, Cummings JH: Selective stimulation of bifidobacteria in the human colon by oligofructose and inulin. Gastroenterol 1995; 108:975-82

24. de Leenheer L, Hoebregs H: Progress in the elucidation of the composition of chicory inulin. Starch 1994:46:193-196.

25. Alles MS, Hartemink R, Meyboon S, Harryvan JL, Van Laere KM, Nagengast FM, Hautvast JG: Effect of transgalactooligosaccharides on the composition of the human intestinal microflora and on putative risk markers for colon cancer. Am J Clin Nutr 1999;69:980-91.

26. Rao AV: Dose-response effects of inulin and oligofructose and intestinal bifidogenesis effects. J Nutr 1999;129(7S):1442S-1445S.

27. Clausen MR, Jorgensen J, Mortensen PB: Comparison of diarrhea induced by ingestion of fructooligosaccharide Idolax and disaccharide lactulose: role of osmolarity versus fermentation of malabsorbed carbohydrate. Dig Dis Sci 1998;43:2696-707.

28. Roberfroid MB, van Loo JAE, Gibson GR. A review of the bifidogenic nature of chicory inulin and its hydrolysis products. J Nutr. 1997;128:1 1-9.

29. Pachenari A: An investigation of the potential of selected strains of Bifidobacterium to colonise the gastrointestinal tract of mice. $1997 \mathrm{PhD}$ thesis. University of New South Wales, UNSW Sydney, Australia.

30. Vaughan EE, Heilig HGHJ, Zoetendal EG, Satokari R, Collins JK, Akkermans ADL, de Vos WM. Molecular approaches to study probiotic bacteria. Trends Food Sci \& Technol 1999;10:400-04.

31. Kruse HP. Kleessen B. Blaut M: Effects of inulin on faecal bifidobacteria in human subjects. Brit J Nutr. 1999;82(5):375-82.

32. Ballongue J. Schumann C. Quignon P: Effects of lactulose and lactitol on colonic microflora and enzymatic activity. Scand J Gastroenterol 1997 : 32(Suppl 222):41-4.

33. Williams CH, Witherly SA., Buddington RK Influence of dietary neosuga on selected bacterial groups of the human faecal microbiota. Microbial Ecol Health Dis 1994;7:91-7.

34. Bouhnik Y. Flourie B. Dagayabensour L. Pochart P. Gramet G. Durand M. Rambaud JC. Administration of transgalacto-oligosaccharides increases fecal bifidobacteria and modifies colonic fermentation metabolism in healthy humans. J Nutr 1997;127:444-8.

35. Bouhnik Y. Flourie B. Riottot M. Bisetti N. Gailing MF. Guibert A. Bornet F. Rambaud JC: Effects of fructo-oligosaccharides ingestion on fecal bifidobacteria and selected metabolic indexes of colon carcinogenesis in healthy human. Nutr \& Cancer. 1996;26:21-9

36. Kleesen B, Sykura B, Zunft H-J, Blaut M. Effects of inulin and lactose on fecal microflora, microbial activity and bowel habit in elderly constipated persons. Am J Clin Nutr 1997;65:1397-402.

37. Ito M, Deguchi Y, Miyamouri A, Matsumoto K, Kikuchi H, Matsumoto K Kobayashi Y, Yajiama T, Kan T. Effects of administration of galactooligosaccharides on the human faecal microflora, stool weight and abdominal sensation. Microb Ecol Health Dis 1990:3:285-92

38. Terada A, Hara H, Katoaka M, Mitsuoka T: Effect of lactulose on the composition and metabolic activity of the human faecal flora. Microb Eco Health Dis 1992;5:43-50

39. Hayakawa K, Mizutani J, Wada K, Masai T, Yoshihara I, Mitsuoka T. Effects of soybean oligosaccharides on human faecal microflora. Microb Ecol Health Dis 1990;3:293-303.

40. Benno Y, Endo K, Shiragami N, Sayama K, Mitsuoka T: Effects of raffinose intake on human fecal microflora. Bifidobacteria Microflora 1987:6:59-63.

41. LetellierA, Messiek S, Lessard L, Quessy S: Assessments of various treatments to reduce carriage of Salmonella in swine. Can J Vet Res 2000; 64:27-31.

42. Pedersen AB, Sandström B, van Amelsvoort JMM: The effect of ingestion of inulin on blood lipids and gastrointestinal symptoms in healthy females. Br J Nutr 1997:78:215-22.

43. Fiordaliso M, Kok N, Desager JP, Goethals F, Deboyser D, Roberfroid M, Delzenne N: Dietary oligofructose lowers triglycerides, phospholipids and cholesterol in serum and very low density lipoproteins in rats. Lipids 1995;30:163-7.

44. Djouzi Z, Andrieux C: Compared effects of three oligosaccharides on metabolism of intestinal microflora in rats inoculated with a human faecal flora. Br J Nutr 1997;78:313-24.

45. Tortuero F, Fernández E, Rupérez P, Moreno M: Raffinose and lactic acid bacteria influence caecal fermentation and serum cholesterol in rats. Nut Res 1997:17:41-9.

46. Jackson KG, Taylor GR, Clohessy AM, Williams CM: The effect of the daily intake of inulin on fasting lipid, insulin and glucose concentrations in middle-aged men and women. Br J Nutr 1999;82:23-30.

47. Davidson MH, Maki KC, Synecki C, Torri SA, Drennan KB: Effects of dietary inulin on serum lipids in men and women with hypercholesterolemia. Nutr Res 1998;18:503-17.

48. Luo J, Rizkalla SW, Alamowitch C, Boussairi A, Blayo A, Barry J-L, Laffitte A, Guyon F, Bornet FRJ, Slama G: Chronic consumption of shortchain fructoligosaccharides by healthy subjects decreased basal hepatic glucose production but had no effect on insulin-stimulated glucose metabolism. Am J Clin Nutr 1996;63:939-45.

49. Brommage R, Binacua C, Antille S, Carrie AL: Intestinal calcium absorption in rats is stimulated by dietary lactulose and other resistant sugars. J 
Nutr 1993;123:2186-94.

50. Delzenne N, Aertssens J, Verplaaetse H, Roccaro M, Roberfroid M: Effect of fermentable fructo-oligosaccharides on mineral, nitrogen and energy digestive balance in the rat. Life Sci 1995;57:1579-87.

51. Ohta A, Ohruki M, Takiza T, Inaba H, Adachi T, Kimura S: Effects of fructooligosaccharides on the absorption of magnesium and calcium by cecectomized rats. Int J Vitain Nutr Res 1994;316-23.

52. Scholz AG, Van Amelsvort JM, Beynen AC: Dietary native resistant starch but not retrograded resistant starch raises magnesium and calcium absorption in rats. J Nutr 1993;123:1724-31.

53. Ohta A, Ohtuski M, Baba S, Hirayama M, Adachi T: Comparison of the nutritional effects of fructo-oligosaccharides of different sugar chain lengths in rats. Nutr Res 1998;18:109-20.

54. Coudray C, Bellanger C, Castiglia-Delavaud C, Remésy C, Vermorel M, Rayssignuier Y: Effect of soluble or partly soluble dietary fibres supplementation on adsorption and balance of calcium, magnesium, iron and zinc in healthy young men. Eur J Clin Nutr 1997;51:375-80.

55. van der Heuval EGHM, Schaafsma G, Muys T, nan Dokkum W. Nondigestible oligosaccharides do not interfere with calcium and nonheme-iron absorption in young healthy men. Am J Clin Nutr 1998;67:445-51.

56. van der Heuval EGHM, Muys T, van Dokkum W, Schaafsma G: Oligofructose stimulates calcium absorption in adolescents. Am $\mathbf{J}$ Clin Nutr 1999;69:544-8

57. Luo J, Van Yperselle M, Rizkalla SW, Rossi F, Bornet, FRJ, Slama G: Consumption of short-chain fructooligosaccharides does not affect basal hepatic glucose production or insulin resistance in type 2 diabetics. J Nutr 2000;6:1572-7.

58. Hunter JO. Tuffnell Q. Lee AJ: Controlled trial of oligofructose in the management of irritable bowel syndrome. J Nutr 1999;129(Suppl 7): $1451 \mathrm{~S}-1453 \mathrm{~S}$.

59. Oli MW, Petschow BW, Buddington RK: Evaluation of fructooligosaccharide supplementation of oral electrolyte solutions for treatment of diarrhoea. Recovery of the intestinal bacteria. Dig Dis Sci 1998;43:138-47.

60. Rowland IR, Tanaka R. The effects of transgalactosylated oligosaccharides on gut flora metabolism in rats associated with human faecal microflora. J Appl Bacteriol 1993;74(6):667-74.

61. Rowland IR, Bearne CA, Fischer R, Poolzobel BL. The effect of lactulose on DNA damage induced by DMH in the colon of human flora-associated rats. Nutr \& Cancer 1996;26(1):37-47.

62. Reddy BS, Hamid R, Rao CV: Effect of dietary oligofructose and inulin on colonic preneoplastic aberrant crypt foci inhibition. Carcinogenesis 1997;18:1371-4

63. Rowland IR, Rumney CJ, Coutts JT, Lievense LC. Effect of Bifidobacterium longum and inulin on gut bacterial metabolism in rats associated with a human faecal microflora. Carcinogenesis 1999;19;281-5.

64. Taper HS, Delzenne NM, Roberfroid MB: Growth inhibition of transplantable mouse tumours by non-digestible carbohydrates. Int J Cancer 1997;71:1109-112.

65. Pierre F, Perrin P, Champ M, Bornet F, Meflah K, Menanteau J: Short-chain fructo-oligosaccharides reduce the occurrence of colon tumours and develop gut-associated lymphoid tissue in Min mice. Cancer Res 1997;57:225-8.

66. Hughes R, Rowland IR. Stimulation of apoptosis by two prebiotic chicory fructans in the rat colon. Carcinogenesis. 2001;22:43-7.

67. Fontaine N, Meslin JC, Lory S, Andrieux C. Intestinal mucin distribution in the germ free rat and in the heteroxenic rat harbouring a human bacterial flora: effect of inulin in the diet. Brit J Nutr 1996;75:881-92.

68. Cassidy MM, Satchithanandam S, Calvert RJ, Vahouny GV, Leeds AR Quantitative and qualitative adaptions in gastrointestinal mucin with dietary fiber feeding. In:Dietary Fiber: Chemistry, Physiology, and Health Effects, Eds Kritchevsky D, Binfield, Anderson JW. Plenum Press, London. 1990;pp67-88.

69. Napoli JEAC, Miller B: Effects of galacto-oligosaccharides on breath hydrogen and gastrointestinal symptoms. Proc Nutr Soc Aust 2000;24.

70. Bouhnik Y, Vahedi K, Achour L, Attar, A, Salfati J, Pochart, P, Marteau P, Flourie B, Rambaud JC: Short-chain fructo-oligosaccharide administration dose-dependently increases fecal bifidobacteria in humans. J Nutr 1999; 129:113-6.

71. Anderson AH, Levine AS, Levitt MD: Incomplete absorption of the carbohydrate in all-purpose wheat flour. N Engl J Med 1981;304:891-2.

72. Stephen AM: Starch and dietary fibre: their physiological and epidemiological relationships. Can J Physiol Pharmacol 1991;69:116-20.

73. EURESTA Euresta Newsletter 1991;11:1.

74. Asp NG, van Amelsvoort JMM, Hautvast JGAJ. Nutritional implications of resistant starch. Nutr Res Rev 1996;9:1-31.

75. Annison G, Topping DL: Resistant starch: chemical structure vs physiological function. Ann Rev Nutr 1994;14:297-320.

76. Brown IL, McNaught KJ, Moloney E. Hi-maizeTM: new directions in starch technology and nutrition. Food Aust 1995;47:272-5.

77. Sievert D, Pomerantz Y: Enzyme-resistant starch I. Characterisation and evaluation by enzymatic, thermoanalytical and microscopic methods. Cereal Chem 1989;66:342-7.
78. Muir JG, Birkett A, Brown I, Jones G, O'Dea K: Food processing and maize variety affects amounts of starch escaping digestion in the small intestine. Amer J Clin Nutr 1995;61:792-9.

79. Englyst HN, Kingman SM, Hudson GJ, Cummings JH: Measurement of resistant starch in vitro and in vivo. Br J Nutr 1996;75:749-55.

80. Noakes M, Clifton PM, Nestel PJ, Leu RL, McIntosh G: Effect of highamylose starch and oat bran on metabolic variables and bowel function in subjects with hypertriglyceridemia. Am J Clin Nutr 1996;64:944-51.

81. Topping DL, Warhurst M, Illman RJ, Brown IL, Playne MJ, Bird AR: A high amylose (amylomaize) starch and fructooligosaccharide increase fecal excretion of bifidobacteria in pigs fed live Bifidobacterium longum. Proc Nutr Soc Aust 1997;21:134.

82. Brown I, Wang X, Topping DL, Playne MJ, Conway PL: High amylose maize starch as a versatile prebiotic for use with probiotic bacteria. Food Aust 1998;50:602-9.

83. Okamoto T. Sasaki M. Tsujikawa T. Fujiyama Y. Bamba T. Kusunoki M: Preventive efficacy of butyrate enemas and oral administration of Clostridium butyricum M588 in dextran sodium sulfate-induced colitis in rats. J Gastroenterol. 2000;35(5):341-346.

84. Kuroaki T, Iwanaga M, Kobari K, Higashionna A, Kinjyo F, Saito A: Preventive effect of Clostridium butyricum M588 against the proliferation of Clostridium difficile during antimicrobial therapy. J Japanese Assoc Infect Dis 1990;64:1425-32.

85. Wang X, Conway PL, Brown IL, Evans AJ: In vitro utilization of amylopectin and high amylose maize (amylomaize) starch granules by human colonic bacteria. Appl Environ Microbiol. 1999;56:4848-54.

86. Sylvi S, Rumney CJ, Cresci A, Rowland IR. Resistant starch modifies gut microflora and microbial metabolism in human flora-associated rats inoculated with faeces from Italian and UK donors. J Appl Microbiol 1999; 86:521-30.

87. Kleesen B, Stoof G, Proll J, Schmiedl D, Noack J, Blaut M. Feeding resistant starch affects fecal and cecal microflora and short chain fatty acids in rats. J Anim Sci 1997;75:2453-2462.

88. Ramakrishma BS, Venkataraman S, Srinivasan P, Dash P, Young G, Binder $\mathrm{HJ}$ :Resistant starch as adjuvant in oral rehydration therapy of cholera in adults. New Engl J Med 2000;342:308-13.

89. Treptow-van Lishaut S, Rechkemmer G, Rowland I, Dolara P, Pool-Zobel $\mathrm{BL}$ : The carbohydrate crystalean and colonic microflora modulate expression of glutathione S-transferase subunits in colon of rats. Eur J Nutr 1999;38:76-83.

90. Hylla S, Gostner A, Dusel G, Anger H, Bartram HP., Christl SU, Kasper H, Scheppach W: Effects of resistant starch on the colon in healthy volunteers possible implications for cancer prevention. Am J Clin Nutr 1998; 67:136-42

91. Heijnen MLA, Vanamelsvoort JMM, Deurenberg P, Beynen AC. Limited effect of consumption of uncooked (RS2) or retorgraded (RS3) resistant starch on putative risk factors for colon cancer in healthy men. Am J Clin Nutr 1998;67:322-31.

92. Ahmed R, Segal I Hassan H: Fermentation of dietary starch in humans. Am J Gastroenterol 95:1017-20.

93. Cassidy A, Bingham SA, Cummings JH. Starch intake and colorectal cancer risk: an international comparison. Br J Cancer 1994;69:937-42.

94. Schulz AGM. Vanamelsvoort JMM. Beynen AC. Dietary native resistan starch but not retrograded resistant starch raises magnesium and calcium absorption in rats. J Nutr 1993;123:1724-31.

95. Michel C. Kravtchenko TP. David A. Gueneau S. Kozlowski F. Cherbut C: In vitro prebiotic effects of Acacia gums onto the human intestinal microbiota depends on both botanical origin and environmental $\mathrm{pH}$ Anaerobe 1998;4:257-66.

96. Parada JL, de Caire GZ, de Mule MCZ, de Cano MMS: Lactic acid bacteria growth promoters from Spirulina platensis. Int J Food Microbiol 1998;3: 225-8.

97. Terada A, Hara H, Mitsuoka T. Effect of dietary alginate on the faecal microbiota and faecal metabolic activity in humans. Microbiol Ecol Health Dis $1996: 8: 259-66$

98. Ho TKH Effects of yeast glucans on the gastrointestinal microflora of mice. 2000; PhD Thesis, University of New South Wales, UNSW Sydney, Australia

99. Wang X, Brown IL, Evans AJ, Conway PL: The protective effects of high amylose maize (amylomaize) starch granules on the survival of Bifidobacterium spp. in the mouse intestinal tract. J Appl Micro 1999;87:631-9.

100.Menne E, Guggenbuhl N, Roberfroid M: Fn-type chicory inulin hydrolysate has a prebiotic effect in humans. J Nutr 2000;5:1197-9.

101.Govers MJAP. Gannon NJ. Dunshea FR. Gibson PR. Muir JG. Wheat bran affects the site of fermentation of resistant starch and luminal indexes related to colon cancer risk: a study in pigs. Gut.1999;45:840-7.

102.Reddy BS: Possible mechanisms by which pro- and prebiotics influence carcinogenesis and tumor growth. J Nutr 1999;129:1478S-1482S

103.Perrin S, Grill JP, Schneider F: Effects of fructooligosaccharides and their monomeric components on bile salt resistance in the species of bifidobacteria. J Appl Microbiol 2000;88:968-74. 